\title{
Por uma crítica da divulgação científica
}

\author{
Gustavo Martineli Massola ${ }^{a}$ \\ José Leon Crochík \\ Bernardo Parodi Svartman ${ }^{\mathrm{a}}$ \\ aUniversidade de São Paulo, Instituto de Psicologia, Departamento de Psicologia Social e do Trabalho. São Paulo, SP, Brasil \\ 'Universidade de São Paulo, Instituto de Psicologia, Departamento de Psicologia da Aprendizagem, do Desenvolvimento e da Person- \\ alidade. São Paulo, SP, Brasil
}

A equipe editorial dedica o seu trabalho referente a este número ao Professor Norberto Abreu e Silva Neto, que foi professor do Instituto de Psicologia da Universidade de São Paulo e do Departamento de Psicologia Clínica da Universidade de Brasília, editor da revista Psicologia: Teoria e Pesquisa e um dos fundadores da revista Psicologia USP.

$* * * * * * * *$

Temos assistido a um debate intenso a respeito da importância da divulgação científica para os periódicos brasileiros. "Divulgação científica" é uma expressão que designa atualmente a transmissão de conhecimento científico para um público leigo no assunto; como acréscimo deveríamos considerar que a divulgação entre os pesquisadores também é científica. Como prática social, pode apresentar objetivos variados e é tão ampla que não se pode abarcá-la toda de uma vez. Inclui iniciativas como a publicação do livro $A$ evolução da Física (Einstein \& Infeld, 2008/1938); a criação do canal de TV Discovery Channel, em 1985; o lançamento da revista Superinteressante, em 1987 ou da enciclopédia Conhecer, em 1966; a publicação em 1982 da revista Ciência Hoje, quando Carolina Bori estava à frente da Sociedade Brasileira para o Progresso da Ciência ("Ciência e política no Brasil das últimas décadas," 1998); o convite a especialistas para falar na Câmara ou no Senado Federal (ver, p. ex., "Violência contra mulher é global e indiscriminada," 2013); um artigo escrito por Salvador Luria na Scientific American (Luria, 2010); o livro Geografia de Dona Benta, de Monteiro Lobato (1987); e livros que são quase uma divulgação científica para outros cientistas não-especialistas, como a Introdução à História da Matemática (Eves, 2008). Em muitos casos, a divulgação científica e a criação de conhecimento científico quase se identificam, como podemos depreender dos conselhos de Becker (2015) sobre como um cientista social deve escrever: de maneira simples, evitando o uso de palavras inusitadas e longos períodos, a fim de ser lido não apenas por especialistas, mas também pelo público interessado mais amplo; em relação a esses conselhos devemos nos perguntar se não contribuem para a diminuição da precisão científica em nome da disseminação e, caso isso ocorra, precisaríamos avaliar se divulgação e ciência não passam a se tornar processos distintos.

Livros de divulgação científica são escritos, bem como demonstrações públicas de Física, Medicina e Química são realizadas sistematicamente, pelo menos desde o século XVIII. No início da ciência moderna, "as divisões entre pesquisa científica e popularização, entre pesquisa, formação de profissionais e entretenimento eram muitas vezes praticamente inexistentes." (Silva, 2006, p. 55). Nesta maneira de entender o assunto, a atividade propriamente científica, de caráter teórico, já é confundida aos olhos públicos com seus resultados práticos, de caráter, se assim podemos nos expressar, tecnológico. Mas torna claro que a divulgação científica acompanha há muitos séculos a pesquisa científica. Este conjunto, porém, tomado em sua generalidade, engana por identificar a "divulgação científica" do século XVIII, momento em que se constituía a profissionalização da ciência, com o momento atual, em que a ciência se estrutura institucionalmente em grandes grupos de pesquisa, públicos ou privados, que consomem quantias significativas do PIB mundial e adota formas organizacionais que reproduzem aquelas encontradas em grandes corporações: dadas as mudanças na própria ciência como instituição, podemos inferir uma modificação em sua relação com a sociedade e, nas ciências humanas, isso parece ocorrer também devido à mudança de estudos autorais para estudos temáticos.

A divulgação científica, por sua vez, ganha dimensões jamais vistas (Silva, 2006, p. 54). O blog SciELO em Perspectiva, por exemplo, tem a intenção de promover "o movimento de acesso aberto em relação ao conhecimento científico" (SciELO, n.d.). Em suas comunicações com os editores, o SciELO afirma que o braço deste blog dedicado às humanidades tem como objetivo central "contribuir para o desenvolvimento, disseminação e marketing dos periódicos das ciências humanas indexados no SciELO" e para "o aumento da visibilidade e credibilidade dos periódicos publicados no Brasil" (SciELO, n.d.). Pode ser necessário atualmente defender esses periódicos e o próprio SciELO, tendo em vista os ataques sistemáticos à publicação científica em acesso aberto, de forma gratuita para o autor e sustentada com recursos públicos (como exemplo destes ataques, ver Beall, 2015). Essas críticas feitas pelos representantes dos publishers ao modelo aberto se apoiam 
basicamente no argumento de que as empresas pagas ofereceriam um melhor serviço de divulgação da produção científica e por isso a tornam mais visível. $\mathrm{O}$ fato de que o SciELO seja alvo de ataques dos publishers e dos seus representantes revela em que medida essa iniciativa representa uma ameaça à privatização do conhecimento e ao interesse das empresas que visam lucro na área da produção e divulgação científica. A construção de uma base de dados aberta pode ser entendida em si mesma como uma importante plataforma de divulgação que caminha numa tendência contra-hegemônica em relação à tendência de mercantilização da divulgação científica. No entanto, é preciso considerar que na própria produção científica e nas suas formas de divulgação estão presentes a racionalidade econômica e a mediação da totalidade social que se pretende criticar. Uma reflexão que possa acompanhar as contradições da divulgação científica e realizar sua crítica imanente precisa reconhecer e analisar esse processo, relacionando-o aos conflitos e interesses sociais presentes nesse campo, com o objetivo explícito de detectarmos as forças que aproximam a divulgação científica da pseudoformação e da pseudocultura.

Um dos motivos subjacentes à divulgação refere-se, segundo Luiz (2006), à necessidade dos cientistas de "prestar contas à sociedade sobre as realizações na área" (p. 53) e explica: "A comunicação da ciência ao público é a forma pela qual os cientistas ganham apoio popular para a institucionalização de seu trabalho" (p. 49). Esta opinião pode ser encontrada em muitos lugares, como em Amorin (2004) ou em Castilho e Facó (2011), que afirmam: "a função social da Divulgação Científica (...) nada mais é que a de prestar contas à sociedade civil dos investimentos que dela saem para geração de conhecimento que para ela deve voltar" (p. 4); com esse argumento, contudo, cabe perguntar se a importância da ciência, sobretudo a básica e a teórica, não se perde, devido ao imediatismo e ao pragmatismo. O risco presente nesta lógica da "prestação de contas" é a utilização de uma lógica contábil e instrumental na própria linguagem científica, que pode ser contrária à intenção inicial da pesquisa, uma vez que se opera neste caso a separação entre o conteúdo do conhecimento produzido e a forma pela qual é divulgado, indicando, tal como expresso antes, que seriam duas atividades distintas.

$\mathrm{O}$ que significa este conhecimento que para ela deve voltar, porém, permanece indefinido. Prestar contas, neste caso, pode ter acepções distintas. Consideremos um projeto amplo de melhoria genética de plantas, voltado ao aprimoramento da produção agrícola, ou um novo processo de geração de álcool combustível: o que interessa à sociedade tem a ver com a eficiência do novo processo ou produto e seu impacto econômico. Consideremos, por outro lado, o longo trabalho de pesquisadores em busca da solução para o último teorema de Fermat. John Lynch, que filmou um documentário sobre o assunto, opinou: "Rapidamente percebi que aquele era um assunto que talvez apenas meia dúzia de pessoas em todo o mundo poderia compreender. Por um momento, pensei se não seria loucura tentar fazer um filme sobre aquele tema" (Lynch, 2014). Suas reflexões sobre o que significava explicar a um grande público o processo que levou à resolução deste importante problema matemático são úteis para a nossa discussão:

Houve um momento, em minha pesquisa, em que busqueiuma justificativa para que o Último Teorema interessasse a alguém que não fosse matemático e por que seria importante fazer um programa a seu respeito. A matemática tem uma infinidade de aplicações práticas, mas no caso da teoria dos números as aplicações mais importantes que encontrei foram na criptografia, no projeto de revestimento acústico e nas comunicações com espaçonaves distantes. Não era provável que isso despertasse uma grande audiência. E o mais interessante eram os próprios matemáticos e a paixão que demonstravam quando falavam de Fermat. (Lynch, 2014)

Esses exemplos talvez sejam suficientes para apoiar o ponto aqui sob discussão: "prestar contas à sociedade" não tem uma acepção unívoca e confunde sob uma mesma expressão processos distintos, desde a avaliação do sucesso relativo de um produto tecnológico até a narrativa "épica" de uma busca intelectual sem qualquer aplicação prática imediata. Novamente, a atividade científica, que é essencialmente teórica - a busca pela representação matematizada de fenômenos empíricos, ou seja, por sua depuração lógico-conceitual -, encontra-se subsumida pelo privilégio dado a suas aplicações tecnológicas, que envolvem, além da ciência, a cultura, a política e outras esferas sociais. Podemos adiantar que o resultado deste processo é uma imagem distorcida da atividade científica, que identifica ciência e tecnologia e impede, mais do que ajuda, a pensar sobre as relações problemáticas entre ciência e sociedade, especialmente se considerarmos o papel da ciência (e não ainda da tecnologia) nos processos de dominação social.

Oliveira (2002) aponta ainda uma razão propriamente política para a divulgação, quando afirma que ciência e tecnologia (C\&T) têm amplas consequências sociais e estão no centro das políticas públicas no Brasil; por isso, "democracia participativa requer cultura científica do eleitorado, para que este seja capaz de apoiar, ou não, as propostas e decisões de seus representantes, e de endossar ou não sua eleição." (p. 12). A divulgação científica sustenta-se sobre razões políticas, portanto, voltadas para as escolhas feitas socialmente e que permitem o direcionamento de recursos para certas atividades de pesquisa, levando à sustentação e recrudescimento de certas linhas de ação e, eventualmente, ao abandono de outras. Se forma e conteúdo não se separam, os periódicos geram conhecimento por meio de suas linhas editoriais, por seus editoriais, pela seleção e ordenamento de artigos a serem apresentados em determinado volume, pelo que consideram fundamental apresentar em cada artigo; difundem esse conhecimento e, por sua vez, ao menos no Brasil, também consomem vultosos recursos públicos - o que faz surgir a necessidade 
de que, também eles, dediquem-se à ampla divulgação do que publicam. Usando as palavras escolhidas pelo SciELO, uma divulgação pobre pode resultar na perda de credibilidade dos periódicos e levar a sociedade a questionar se é oportuno continuar a sustentá-los.

Na ideia de divulgar para prestar contas está implícita uma separação institucional entre ciência e sociedade, aquela tomada como uma atividade profissional sustentada por recursos públicos (em alguns casos, privados) cuja destinação depende de escolhas políticas. Esta imagem não deixa de estar correta, mas dá o que pensar. Por um lado, esta separação parece desconsiderar que a ciência é uma instituição da sociedade e relaciona-se intrinsecamente com sua totalidade, que, apesar de haver conquistado autonomia frente a outras atividades sociais, "ela se dá, e sempre se deu, dentro da sociedade, e esta autonomia é apenas relativa." (Silva, 2006, p. 55). Há, por outro, um conjunto de conhecimentos que não tem como ser adequadamente explicado para o público mais amplo, exceto de forma distorcida, como reconheceu Lynch, ainda que, para os que defendem o esclarecimento e a consciência, pudesse ser publicado caso se confie na capacidade dos leitores de entender esses conhecimentos. Se a ideia de prestar contas for levada ao extremo, o que não pode ser divulgado deve ser rechaçado, e isso deveria implicar o banimento de inúmeras áreas do conhecimento, entre elas, quiçá, a teoria dos números. Além da separação institucional, a relação entre ambas é pensada como uma pela qual a ciência serve à sociedade. Nesta posição, o termo "sociedade" é posto como instância de julgamento e avaliação da atividade científica, desse modo, a ciência seria reduzida à sua aplicação, isto é, à sua vertente pragmática, ou ainda, ao Positivismo, na manutenção do progresso dentro da ordem e, nessa redução, negar-se-ia sua vertente de busca da verdade, privilegiando os procedimentos e os resultados: o como os fenômenos ocorrem, mas não o porquê. Em alguns casos, porém, a relação parece ser exatamente oposta a esta.

Giddens (1991), por exemplo, após elogiar a concepção marxiana de usar a história para fazer história, discorre sobre a sociologia e afirma que o conhecimento por ela desenvolvido "espirala dentro e fora do universo da vida social, reconstituindo tanto este universo como a si mesmo como uma parte integral deste processo" (p. 24), e que, apesar de não deixar de produzir profundos efeitos sobre a sociedade, "não leva de maneira direta a um mundo social transparente" (p. 24). O resultado é uma dupla hermenêutica pela qual a ciência interpreta a vida social assim como os agentes sociais; por sua vez, apropriam-se deste conhecimento de formas heterogêneas levando a mudanças sociais imprevisíveis e fora de controle pleno por qualquer que seja o agente social, "nem por aqueles que os propõem, nem mesmo por grupos poderosos ou agências governamentais" (p. 24). Neste caso, se ninguém pode controlar este conhecimento e nem conhecer suas consequências sobre a vida social, quem deveria julgar sua pertinência ou adequação? Tomemos, por outro lado, o exemplo da psicanálise, aqui entendida em seu sentido original que inclui um esforço científico. Se agora ela em grande medida converteu-se em conhecimento voltado para o ajuste e a adaptação do indivíduo à sociedade, não se pode esquecer que em algum momento Freud considerou que, com sua criação, havia trazido a peste à humanidade. A quem deveria reportar-se um psicanalista atuante em universidades que, imbuído deste espírito perturbador, quisesse prestar contas de suas pesquisas? A imagem da divulgação científica, assim considerada, toma "a sociedade" como um conjunto homogêneo e coeso, quando ela se apresenta plena de contradições e rupturas. A divulgação científica bem pode servir, neste caso, para justificar esta imagem ideológica segundo a qual a sociedade é definida por sua coesão, mas não faz jus à própria atividade científica. Chauí (1989) faz a seguinte reflexão sobre a física moderna: "O saber galilaico torna-se aceitável e passível de incorporação quando já foram acionados dispositivos econômicos, sociais e políticos que permitam acolher o saber novo não porque seja inovador, nem porque seja verdadeiro, mas porque perdeu a força instituinte, já se transformou de saber sobre a natureza em conhecimentos físicos, já foi neutralizado, e pode servir para justificar a suposta neutralidade racional de uma certa forma de dominação" (p. 6). Certamente, a relação entre ciência e política não é tão imediata e sem contradições, mas o exagero, se é que se trata de exagero, revela o risco que se corre. O conhecimento científico pode ter, e muitas vezes tem, caráter disruptivo e transformador, que não cabe na bem-comportada imagem de sua divulgação. Divulgar a ciência, por outro lado, pode servir a interesses de dominação bastante específicos, e aqui não precisamos sequer concordar com Giddens (1991) a respeito da impossibilidade de qualquer grupo de controlar a vida social com o uso do conhecimento sociológico. Neste sentido, talvez a ciência "sirva" à sociedade. E, se ainda for possível lutar contra este grande mal, o trabalho científico necessitará de ampla liberdade frente a instâncias sociais de julgamento que, ao contrário, terão muito interesse em que os cientistas lhes prestem contas. Em muitas ocasiões, a ciência é que se instituiu como instância julgadora da sociedade e não hesitou em apontar-lhe os defeitos, o que remonta à discussão de Marcuse (1981), que indica que, na Grécia de Sócrates, Platão e Aristóteles, verdade e ética não eram separáveis, pois conhecer era conhecer o 'ser' e não o 'não-ser'; o conhecimento deveria servir a vida e não à destruição. É importante reconhecermos essa tendência presente no próprio desenvolvimento da ciência, que, como apontaram Horkheimer e Adorno (2014), como uma das formas de esclarecimento, sempre serviu ao poder, mas também à sua oposição.

Quando a ciência passa a servir a interesses sociais específicos, muitas vezes ela o faz em favor de grupos detentores do poder econômico necessário para financiar pesquisas ou definir as linhas de financiamento do poder público. Este direcionamento pode ser feito sem que se ataque a própria ciência, ou melhor, pode ser feito no mesmo movimento pelo qual se a valoriza, surgindo um contexto social de "hipervalorização do conhecimento dito 
científico e de simultânea repressão ao trabalho científico" (Chauí, 1989, p. 7), o que apenas aparentemente constitui um paradoxo:

assim, não é paradoxal nem contraditório em um mundo como o nosso, que cultua patologicamente a cientificidade, surgirem interdições ao discurso científico. Podemos dizer que exatamente porque a ideologia contemporânea é cientificista, cabe-lhe o papel de reprimir o pensamento e o discurso científico. (Chauí, 1989, p. 7)

Enfim, ao contrário do que talvez pareça, a consequência desta discussão não é a defesa do uso irrestrito de recursos públicos pelos cientistas, mas antes a crítica a uma forma de pensar a ciência pela qual só se valoriza aquilo que é apoiado por grandes somas de recursos. Este modelo pelo qual se relacionam ciência e sociedade é relativamente recente e já foi discutido anteriormente por um grande número de pesquisadores. Ele de fato transforma a ciência num complexo empreendimento comercial que, como qualquer outro empreendimento deste tipo, necessita também apresentar ao estado seus balanços contábeis.

Além desse, outro problema se apresenta: quando se fala em divulgação científica em periódicos, o que é que se pretende divulgar? A pergunta tem o seguinte sentido: traduzir para leigos ideias produzidas no contexto de um argumento científico implica em alguma medida traduzir o argumento inteiro, o que exige um trabalho talvez tão complexo quanto o da própria pesquisa e/ou estudo. Uma alternativa é retirar do argumento apenas as afirmações que interessa divulgar apresentando-as fora de seu contexto original ou reduzindo-o a suas partes mais elementares. Neste caso, temos a divulgação dos resultados do conhecimento científico (não nos referimos aqui a seus produtos tecnológicos) sem que seja apresentada a forma ou o método pelo qual eles foram criados. O efeito deste tipo de deslocamento não é o de aumentar o conhecimento do público leigo sobre aquela área do conhecimento, mas o de distanciá-lo. O resultado do conhecimento torna-se um fetiche repetido indefinidamente sem qualquer substância. Um conhecido site humorístico dedicado à pós-graduação em ciências exatas publicou uma charge com a legenda: "Você pode ignorar com segurança qualquer sentença que inclua a frase 'de acordo com a mecânica quântica"' e explicou:

Este quadrinho brinca com o fato de que a mecânica quântica é um assunto muito complexo que é frequentemente mal aplicado pelos leigos. Muitos dos fenômenos estudados em mecânica quântica são contraintuitivos e só podem ser expressos em matemática complexa. Mesmo assim, como o campo é fundamental para nossa compreensão da realidade, ele é frequentemente citado para apoiar generalizações filosóficas amplas e deslumbrantes. ("1240: Quantum Mechanics explain xkcd,” 2013).
Todos conhecemos os misteriosos efeitos psíquicos atribuídos aos processos quânticos, mas nem sempre este deslocamento é tão inocente. Cohen (1998) nos alerta em seu documentário sobre os perigos decorrentes do deslocamento falacioso de afirmações de um campo do conhecimento a outro ao analisar o movimento eugenista, de grande influência no início do século XX. Ao apoiá-lo "cientificamente", encontrava-se a incorporação despreocupada de afirmações a respeito da sobrevivência dos mais aptos, retiradas do conjunto de argumentos sobre a teoria da evolução das espécies e importadas acriticamente para uma teoria da sociedade. Seus efeitos sobre a psicologia como área do conhecimento são bem evidentes no desenvolvimento dos testes de inteligência, cuja crítica pode ser encontrada em Gould (1996); resta indagar se essa associação, feita por Gould, não perde a contradição, ao se pensar que esses testes também poderiam, por vezes, ter objetivos emancipatórios.

Desta forma, torna-se necessário refletir sobre as condições em que a divulgação do trabalho científico implica a destruição do que há de mais essencial neste empreendimento cultural. Se o que nos espanta são seus resultados, aquilo que o distingue de toda outra forma de conhecimento são seus métodos e a contraposição ou confirmação do que já se conhece. O caráter científico de um conhecimento não se define somente por seu conteúdo, mas também pela forma como foi obtido, o que permitiria que o próprio conteúdo esteja sempre sujeito ao falseamento; frente a essa afirmação cabe perguntar, no entanto, se o método não deve servir ao objetivo científico. Essa questão põe em dúvida a referente ao falseamento, que restringe a compreensão contraditória da realidade. $O$ conteúdo de uma afirmação científica, abstraído de seu contexto argumentativo, pode assumir um caráter fetichizado e a-crítico que impede o pensamento em vez de fomentá-lo e, ainda mais grave, torna opaco ao público leigo o processo pelo qual é (ou deveria ser) ininterruptamente criticado no interior da própria atividade científica. Por outro lado, o efeito deste tipo de divulgação pode ser uma admiração quase supersticiosa pelo trabalho do cientista - ao fim e ao cabo, a ciência transforma-se em mito. Se isso é pernicioso do ponto de vista da compreensão da ciência pelo público leigo, combina muito bem com o primeiro objetivo aqui apontado para a divulgação científica: conseguir apoio institucional para o trabalho do cientista. Um público incapaz de compreender o conhecimento científico é de fato um público a ele submetido.

A divulgação assim entendida tem como efeito impedir ao público a compreensão em profundidade da forma mais difundida e aceita de criação de verdades em nossa sociedade, a forma "de maior prestígio e legitimidade atualmente" (Silva, p. 56). Impede, portanto, a própria compreensão do mundo social e condena as grandes massas a permanecer "nas trevas, sem experiência, vivendo o dia-a-dia", conforme as palavras de Goethe. Este efeito alienante, para o qual pode contribuir a divulgação científica, deve ser considerado em 
suas consequências mais graves. Weil (1996), ao discorrer sobre o sentimento moderno de desenraizamento, qualifica-o como "a mais perigosa doença das sociedades humanas" (p. 414) e considera diretamente sua relação com nosso tema:

O que hoje se chama de instruir as massas é pegar esta cultura moderna elaborada num meio tão fechado, tão deteriorado, tão indiferente à verdade, tirar dele tudo o que ainda pode conter de ouro puro, operação que se chama de divulgação, e enfiar o resíduo, do jeito que está, na memória dos infelizes que querem aprender, como se leva a comida ao bico dos passarinhos. (p. 414)

Mesmo o efeito por outro lado desejável de combater a ignorância por meio da divulgação de informações científicas, quando realizado de forma a desconsiderar essas relações entre ciência e sociedade, pode retirar das massas a possibilidade de interpretar seu próprio mundo, sem a contrapartida de instruírem-nos sobre a maneira pela qual ele é de fato explicado pela cultura científica.

Toda a discussão apresentada até aqui defronta-se com o problema fundamental de saber se essas são características inerentes à divulgação científica. Gostaríamos de argumentar que isso é apenas parcialmente verdadeiro. $\mathrm{O}$ que há de verdadeiro nesta forma de pensar pode ser expresso pela ideia de que a própria expressão "divulgação científica" contém em si parte importante do problema. Em primeiro lugar, porque a atividade em si surge quando a ciência se institucionaliza e começam a surgir cisões simbólicas entre "cientistas" e "não-cientistas":

O que chamamos de divulgação científica é o reflexo de um modo de produção de conhecimento restringido e, conseqüentemente da constituição de um efeito-leitor específico relacionado à institucionalização, profissionalização e legitimação da ciência moderna, e que opõe produtores usuários/ consumidores e, cria a figura do divulgador, que viria, imaginariamente, restabelecer a cisão, e minimizar a tensão instaurada ao longo da história no tecido social da modernidade. Essa cisão não é mantida sem tensão, sem a (re)produção tensa de um imaginário que a mantém. É nesse imaginário que trabalha a divulgação científica. (Silva, 2006, pp. 57-58)

A consequência disso é que a divulgação científica opera pela oposição de dois sujeitos, de um lado, "o sujeito produtor do conhecimento científico numa posição de autoridade altamente legitimada e de outro, o consumidor do conhecimento científico, o sujeito interessado em atualização cultural, sem nenhum conhecimento sobre ciência". (Silva, 2006, p. 58) Uma evidência disso é que, apesar da já mencionada pluralidade da atividade de divulgação, que quase não permite compreendê-la intelectualmente com um único movimento de pensamento, para todas elas emprega-se o mesmo nome, "divulgação científica". Se não há algo que caracterize especificamente um texto de divulgação científica, de onde vem a força desta expressão, que continua a ser usada repetidamente? "Seu efeito não estaria em participar do imaginário necessário à circunscrição de espaços de interlocução, em diferenciar um espaço que seria 'interior' e um espaço que seria 'exterior' à ciência?" (p. 58). A própria atividade de divulgação pode ser considerada responsável pelo mal que ela procura combater e, neste sentido, ele tem caráter necessário nesta atividade. Esta conclusão aponta a possibilidade de que a própria tendência de emancipação presente na produção científica tome a relação entre ciência e sociedade como um assunto fundamental para sua reflexão, incluindo aí as formas pelas quais torna acessível para a sociedade o conhecimento produzido sem aproximá-lo demasiadamente do consumo de mais uma mercadoria, buscando instigar nesse próprio processo a capacidade de reflexão dos indivíduos.

\section{Referências}

1240: Quantum Mechanics - explain xkcd. (2013). Recuperado de http://www.explainxkcd.com/wiki/ index.php/1240:_Quantum_Mechanics

Amorin, D. (2004). Ciência na vitrine. Roberto Lent, professor da UFRJ, esteve na UnB e mostrou as vantagens da divulgação científica e sua importância para o país. Recuperado de http://www.secom.unb.br/ unbagencia/ag0704-12.htm

Beall, J. (2015). Is SciELO a Publication Favela? Recuperado de http://scholarlyoa.com/2015/07/30/is-scielo-apublication-favela/

Becker, H. (2015). Truques da escrita. Rio de Janeiro, RJ: Zahar.

Castilho, A. de, \& Facó, J. F. B. (2011). A divulgação científica na universidade pública: case Universidade
Federal do ABC. In XXXIV Congresso Brasileiro de Ciências da Comunicação (pp. 1-15). Recife, PE: Sociedade Brasileira de Estudos Interdisciplinares de Comunicação. Recuperado de http://www.intercom. org.br/papers/nacionais/2011/resumos/R6-2341-1. pdf

Chauí, M. de S. (1989). Cultura e democracia: o discurso competente e outras falas (4a ed.). São Paulo, SP: Cortez. Recuperado de https://books.google.com/books?hl=ptBR\&id=ynghAQAAIAAJ\&pgis=1

Ciência e política no Brasil das últimas décadas. (1998). Psicologia USP, 9(1), 181-183. http://doi.org/10.1590/ S0103-65641998000100034

Cohen, P. (1998). Homo Sapiens 1900 [filme]. Suécia: Mais Filmes. 
Einstein, A., \& Infeld, L. (2008). A evolução da Física (1st ed.). Rio de Janeiro, RJ: Zahar.

Eves, H. (2008). Introdução à história da matemática. Campinas, SP: Editora da Unicamp.

Giddens, A. (1991). As consequências da modernidade (5a ed.). São Paulo, SP: UNESP.

Gould, S. J. (1996). The mismeasure of man. New York: Norton.

Horkheimer, M., \& Adorno, T. W. (2014). Dialética do esclarecimento: fragmentos filosóficos. Rio de Janeiro, RJ: Zahar.

Lobato, M. (1987). Geografia de Dona Benta (5a ed.). São Paulo, SP: Círculo do Livro.

Luiz, O. do C. (2006). Ciência e risco à saúde nos jornais diários. São Paulo, SP: Annablume.

Luria, S. E. (2010). O mistério T2. In A. C. Ferrari \& L. Pinheiro (Eds.), Prêmios Nobel na Scientific American (pp. 53-59). São Paulo, SP: Duetto. Recuperado de http://doi.org/9788579020902

Lynch, J. (2014). Introdução. In S. Singh (Ed.), O último teorema de Fermat (1st ed.). Rio de Janeiro, RJ: Best Bolso.
Marcuse, H. (1981). Eros e civilização: uma interpretação filosófica do pensamento de Freud. Rio de Janeiro, RJ: Zahar.

Oliveira, F. de. (2002). Jornalismo científico. São Paulo, SP: Contexto.

SciELO. (n.d.). Sobre. Recuperado de http://blog.scielo.org/ sobre/

Silva, H. C. da. (2006). O que é divulgação científica? Ciência \& Ensino, 1(1), 53-59. Recuperado de https:// www.google.com.br/url? sa $=\mathrm{t} \& \mathrm{rct}=\mathrm{j} \& \mathrm{q}=\& \mathrm{esrc}=\mathrm{s} \&$ sour ce $=$ web \&cd $=5 \&$ ved $=0$ CDAQFjAEahUKEwi3zfD8zLn IAhXFgpAKHfSXCp8\&url=http $\% 3 \mathrm{~A} \% 2 \mathrm{~F} \% 2 \mathrm{Fprc}$.ifsp. edu.br $\% 2$ Fojs $\% 2$ Findexphp $\% 2$ Fcienciaeensino $\% 2$ Farti cle $\% 2$ Fdownload $\% 2$ F39\%2F98\&usg=AFQjCNHXr9y Aqljhgi4FqckEfwH15nxpRA

Violência contra mulher é global e indiscriminada. (2013, 6 de dezembro). Jornal do Senado. Recuperado de http://www12.senado.gov.br/jornal/edicoes/2013/12/06/ violencia-contra-a-mulher-e-global-e-indiscriminada

Weil, S. (1996). O desenraizamento. In E. Bosi (Ed.), A condição operária e outros estudos sobre a opressão (pp. 407-440). Rio de Janeiro, RJ: Editora Paz e Terra. 